\title{
Forskning om bruk av psykisk helsevern i Norge
}

\author{
Torleif Ruud, Helle Wessel Andersson, Johan Håkon Bjørngaard, Helge Hagen, \\ Vidar Halsteinli, Torhild Heggestad og Per Bernhard Pedersen
}

Korrespondanse: Torleif Ruud, SINTEF Unimed, Postboks 124 Blindern, 0314 Oslo

Telefon: 22067974 Telefaks 22067909 Mobil: $91362750 \quad$ E-post: Torleif.Ruud@sintef.no

\section{INNLEDNING}

Denne artikkelen beskriver forskning gjort ved SINTEF Unimed Helsetjenesteforskning om det psykiske helsevernet og befolkningens bruk av slike tjenester. Artikkelen gir en oversikt over metoder og materialer som er brukt og orienterer om en del av de tema som er belyst av denne forskningen i løpet av de siste årene. Når det gjelder mer detaljerte funn og diskusjon av dem, henvises det i hovedsak til de publikasjonene som er referert. Denne artikkelen er altså ment å være en veiviser til disse undersøkelsene og publikasjonene. Til slutt drøftes den videre utvikling av dette forskningsfeltet.

Mens befolkningsundersøkelser med tilfeldige utvalg kan gi grunnlag for å anslå forekomst av psykiske lidelser i befolkningen og eventuelt behovet for tjenester innen psykisk helsevern, kan helsetjenesteforskningen med studier av den kliniske populasjonen gi informasjon om forekomst og kjennetegn ved den delen av befolkningen som bruker helsetjenestene og om tilgjengeligheten av slike tilbud. Helsetjenesteforskning ved bruk av pasientregistre har mye til felles med epidemiologisk forskning ved at begge gir kunnskap om insidens og prevalens, selv om de bruker ulike metoder og utvalg.

SINTEF Unimed Helsetjenesteforskning (tidligere Norsk Institutt for Sykehusforskning) består av flere avdelinger med ulik profil. Fra 2001 har en samlet de forskerne som arbeider med det spesialiserte psykiske helsevernet og det psykisk helsearbeidet i kommunene $i$ en egen avdeling kalt Helsetjenesteforskning psykisk helsearbeid. De undersøkelsene og analysene som er omtalt i denne artikkelen, er i hovedsak gjort av forskere som nå arbeider i denne avdelingen. Det har også i enkelte tilfeller vært samarbeid med forskere ved NTNU eller andre forskningsmiljøer om publisering av rapporter eller artikler. SINTEF Unimed Helsetjenesteforskning driver med oppdragsforskning, - og med et psykisk helsevern som i hovedsak er offentlig, er det først og fremst statlige helsemyndigheter som har vært oppdragsgivere og har finansiert denne forskningen. I tillegg har fylkeskommunene finansiert enkelte prosjekter i den tiden de har hatt ansvar for spesialisthelsetjenestene.

Noen problemstillinger som har vært søkt belyst ved denne forskningen er:

- Prevalens for bruk av psykisk helsevern

- Endringer i bruk av psykisk helsevern
- Om pasientene får den type hjelp de har behov for

- Geografiske forskjeller i bruk av tjenester

- Analyser av pasientforløp og reinnleggelser

- Årsaker til variasjon i tvangsinnleggelser

\section{Metoder OG MATERIALER}

\section{Tverrsnittsundersøkelser}

Siden 1979 er det hvert femte år gjennomført en registrering av alle voksne døgnpasienter ved alle psykiatriske institusjoner i Norge på en bestemt dag (1. november). Disse registreringene har gitt informasjon om sosiodemografiske forhold, tidligere behandling, hva slags hjelp pasientene har behov for og mottar, og om de får hjelp på rett omsorgsnivå. Opplysningene er gitt av behandlerne i anonymisert form. Alle institusjoner har levert data, og så langt en vet er det blitt fylt ut skjema på alle pasienter ved hver institusjon. Det er altså hele populasjonen av døgnpasienter på det gitte tidspunktet som er beskrevet, og ikke bare et utvalg.

Disse registreringene har gjennom 20 år vært en av de viktigste kildene for informasjon både om brukerne av døgnavdelinger og om mønsteret $i$ bruk av døgnavdelinger. Pasientregistreringene har vært finansiert av Sosial- og helsedepartementet. Det er publisert en rekke rapporter fra disse registreringene (Øgar 1981, 1983, Øgar et al 1986, Hagen 1987, 1989, 1997, 2001). En del analyser er også presentert i Samdata Psykisk helsevern (se nedenfor), artikler (Kolstad 1988, Kolstad og Hagen 1988, Götestam et al 1995, Bjørngaard og Heggestad 2001) og bokkapitler (Hagen 1991).

Siden disse registreringene har vært gjennomført regelmessig hvert femte år med registrering av stort sett samme type opplysninger, har de også bidratt til kunnskap om hvordan døgntilbudet i psykisk helsevern for voksne har utviklet seg gjennom 20 år. Pasientregistreringene kan altså brukes til å se på endringer i bruk av psykisk helsevern. Men siden de består av anonymiserte data, kan en ikke analysere i hvilken grad det er de samme personene som er brukere av psykisk helsevern over lengre tid.

Siden 1990 er det også gjennomført pasientregistreringer av polikliniske pasienter innen psykisk helsevern for voksne hvert femte år. Disse har vært utformet på samme måte og med mange av de samme variablene som registreringene av døgnpasienter, men med en to ukers registreringsperiode for å få med de fleste pasientene poliklinikkene har kontakt med. Det 
er behandlerne som har fylt ut anonymiserte skjema med opplysninger om pasientene og behandlingen som gis. Materialet fra de offentlige poliklinikkene ved siste pasientregistrering i 2000 antas å være komplett fordi en fikk opplysninger fra alle poliklinikkene. Materialet fra spesialister med selvstendig praksis er mer mangelfullt, i det en fikk opplysninger fra henholdsvis 62 prosent psykiatere og 31 prosent psykologer i forhold til antallet spesialister med selvstendig praksis som helsemyndighetene kjente til.

Etter modell fra pasientregistreringene for voksne, og for å fremskaffe opplysninger av mer vurderende karakter enn de som normal registreres i Bupdata (se nedenfor), ble det i 1999/2000 på oppdrag fra Statens helsetilsyn også gjennomført en landsomfattende registrering av barn og unge med psykiske lidelser som mottar tilbud innen det spesialiserte psykiske helsevernet (Andersson, 2001). Studien omfattet en tverrsnittsregistrering der samtlige barn og unge som mottok institusjonsbehandling 1. november 1999 inngikk. I tillegg ble alle barn og unge som mottok polikliniske tilbud over en 14 dagers periode våren 2000 registrert. Undersøkelsen var basert på behandlernes rapporteringer av hvilke tilbud pasientene faktisk mottok, inkludert ulike behandlingsformer og typer tjenester fra samarbeidende instanser på kommunalt og fylkeskommunalt nivå.

\section{Longitudinelle undersokelser}

På oppdrag fra Sosial- og helsedepartementet har SINTEF Unimed Helsetjenesteforskning utarbeidet årlige nasjonale rapporter om utviklingen innen psykisk helsevern i relasjon til helsepolitiske mål som lik tilgang til tjenester og effektiv ressursutnyttelse. Disse rapportene er kalt Samdata Psykisk helsevern (tidligere Samdata psykiatri) (Pedersen \& Bergsland 1993, Pedersen et al 1994, Heggestad \& Pedersen 1995, Pedersen 1996, 2002, Hatling 1997, Halsteinli 1997, 1998, 1999, 2000, Hagen 1999, 2000, Bjørngaard 2001). De siste årene har de vært publisert som to rapporter, - en tabelldel med et omfattende tabellverk og en rapport som analyserer utviklingen $\mathrm{i}$ det psykiske helsevernet for både barn og unge og for voksne. Dette er parallelle rapporter til Samdata Sykehus, som analyserer bruken av somatiske sykehustjenester. Rapportene distribueres til alle institusjonene i landet og gjøres tilgjengelig via internett (www.samdata.sintef.no).

Samdata Psykisk helsevern baserer seg på flere datakilder. Ressursdata (personell, døgnplasser og regnskap) hentes fra Statistisk Sentralbyrå (SSB), mens opplysninger om befolkningens bruk av tjenester primært hentes fra pasientdata. Pasientdata for voksne hentes fra Norsk Pasientregister, som etter årets slutt samler inn data fra alle institusjoner om alle pasienter og behandlingsepisoder ved institusjonen i løpet av året. For å få komplette nasjonale aktivitetstall, har det i varierende grad vært nødvendig å supplere pasientdata med aktivitetsstatistikk fra SSB.

I de siste utgavene av Samdata Psykisk helsevern bygger pasientdata for voksne på et "minste basis datasett" som ble utformet på midten av 90-tallet. Dette var utformet av EDB-utvalget i Norsk psykiatrisk forening og godkjent av Statens helsetilsyn (Ruud et al 1993), og det ble integrert med det datasettet som SINTEF Unimed Helsetjenesteforskning hadde utviklet over flere år (Heggestad 1993). Sosial- og helsedepartementet påla psykisk helsevern for voksne å registrere disse data fra 2000 om alle pasienter som hadde kontakt med psykisk helsevern. Datasettet ble fra 2001 justert i samsvar med nye helselover når det gjaldt registrering av bruk av tvang. En av de nye variablene som er blitt tatt med i det obligatoriske datasettet, er GAF (Global Assessment of Functioning Scale) (American Psychiatric Association 1994). Ved en todelt skala for henholdsvis globalt symptomnivå og globalt funksjonsnivå vil en forsøke å måle både alvorlighetsgraden av lidelsen og endringer $\mathrm{i}$ denne under behandling. Rapporteringen av GAF-skåringer er foreløpig mangelfull, og det er derfor for tidlig å vite om GAF vil svare til forventningene som et element $\mathrm{i}$ datasettet.

Det er først fra 2000 at myndighetene har krevd rapportering av dette felles datasettet fra alle psykiatriske institusjoner, og det vil fortsatt ta noe tid før alle institusjoner har skaffet de nødvendige pasientadministrative datasystemer og innarbeidet de rutiner som må til for å kunne registrere og rapportere disse opplysningene. A kunne fremskaffe komplette og pålitelige data på individnivå fra det samlede psykiske helsevern fra hele landet, er et stort utviklingsarbeid som ennå ikke er ferdig. Det vil gi bedre informasjon for institusjoner og helsemyndigheter enn det som hittil har vært mulig når en måtte kombinere de data som var tilgjengelig med den variasjon og de mangler dette har representert.

Nasjonal statistikk i Samdata psykisk helsevern om barn og unge som mottar spesialisthelsetjenester, er i hovedsak basert på løpende registreringer i det pasientadministrative datasystemet (Bupdata) som er utviklet $i$ et samarbeid mellom Norsk forening for barne- og ungdomspsykiatriske institusjoner og Hiadata AS. Dette informasjonssystemet omfatter barne- og ungdomspsykiatriske poliklinikker, klinikkavdelinger og behandlingshjem. Bupdata inneholder en rekke variabler og er godt egnet for forskning både på pasientnivå og på helsetjenesten som system. Datasettet er beskrevet $\mathrm{i}$ en egen kodebok (Kodebok for BUP 1999). Samdata psykisk helsevern gir grunnlag for å følge utviklingen av det spesialiserte tjenestetilbudet for barn og unge med psykiske lidelser. Gjennom dette tallmaterialet presenteres i hovedsak informasjon om antall som mottar behandling ved de ulike institusjonene, pasientenes henvisningsgrunner og diagnoser, samt omfanget av bruk av tjenester.

Samdata Psykisk helsevern Tabeller 2000 (Bjørngaard 2001) viser hvordan disse publikasjonene inneholder omfattende informasjon om bruk av psykisk helsevern i 2000 både sett $\mathrm{i}$ forhold til ulike typer institusjoner, $\mathrm{i}$ forhold til fylkene, $\mathrm{i}$ forhold til de fem 
helseregionene og for landet som helhet. Det er også informasjon om ressurser $i$ form av personellinnsats og kostnader. Siste del av rapporten inneholder grunnlagsdata som tabellene bygger på. Denne rapporten med tabeller er i hovedsak beskrivende og er ment som en informasjonskilde for dem som har bruk for slike opplysninger på ulike nivå.

Siden det er gjort innsamling og analyser av en rekke pasientmaterialer både når det gjelder tverrsnittsdata og longitudinelle data, er det $\mathrm{i}$ en orienterende artikkel hverken hensiktsmessig eller mulig å gå gjennom alle disse materialene. Nedenfor blir det derfor $i$ hovedsak referert til de materialer som er samlet inn sist, samt noen analyser på tvers av flere materialer.

\section{RESULTATER}

\section{Prevalens for bruk av psykisk helsevern}

I den siste pasientregistreringen for døgninstitusjoner i november 1999 var det 5084 døgnpasienter (14,1 pr. 10000 voksne innbyggere) i psykisk helsevern for voksne, fordelt på 2763 ved sykehusavdelinger og 2321 ved andre døgninstitusjoner (Hagen 2001). Totalt var det 533 færre døgnpasienter enn i 1994, noe som er en reduksjon på ni prosent. Denne endringen var ulikt fordelt, ved at pasienttallet ved sykehusene hadde økt med seks prosent, mens pasienttallet ved andre typer døgninstitusjoner var redusert med 23 prosent. Fordeling mellom disse andre institusjonstypene er usikker siden kriteriene for kategorisering av distriktspsykiatrisk senter, bo- og behandlingssenter og psykiatrisk sykehjem har vært mangelfull. Ved registreringen av polikliniske pasienter i 2000, kom det inn opplysninger om 13135 pasienter (36,4 pr. 10000 voksne innbyggere) ved psykiatriske poliklinikker for voksne (Hagen 2001). I tillegg kom det inn opplysninger om 2996 pasienter hos psykiatere og 3462 pasienter hos psykologer med selvstendig praksis. Til sammen er dette 19593 polikliniske pasienter.

Ved de tilsvarende pasientregistreringene av barn og unge var det 355 som mottok institusjonsbehandling 1. november 1999, og 6048 som mottok polikliniske tilbud i løpet av en 14 dagers periode våren 2000 (Andersson 2001).

\section{Endringer i bruk av psykisk helsevern}

Myndighetene har gjennom arbeidet med St meld 25 (1996-97) «Åpenhet og helhet. Om psykiske lidelser og tjenestetilbudene» og den påfølgende St prp nr 63 (1997-98) «Om opptrappingsplan for psykisk helse 1999-2006» satt seg klare mål om økt ressursinnsats, omstrukturering av tjenestetilbudene, bedre geografisk fordeling og økt effektivitet. Samdata Psykisk helsevern er et viktig redskap i å følge utviklingen. Ut fra Stortingets behandling av stortingsmeldingen skal disse tjenestene omfatte sykehusavdelinger, distriktspsykiatriske sentra (DPS) og privatpraktiserende spesialister med offentlig driftsavtale.
Analyser av data fra 90-årene viser at det har vært en relativt jevn utvikling i psykisk helsevern. Det har vært en klar økning i omfanget av behandlingstilbudet til barn og unge, og for voksne har det vært en vridning fra lengre institusjonsbehandling til kortere behandlingsopphold ved institusjon og poliklinisk behandling. Antall døgnplasser for voksne er blitt redusert gjennom hele 90-tallet, men med størst reduksjon ved psykiatriske sykehjem og en klar økning av plasser ved bo- og behandlingssentre. Selv om en del av denne økningen skyldes at en del enheter ved sykehus og sykehjem har blitt omgjort eller omklassifisert til enheter ved distriktspsykiatriske sentre eller bo- og behandlingssentre, er en slik utvikling i tråd med den planlagte utbyggingen av desentraliserte tjenester innen psykisk helsevern. En gjennomgang av institusjonsstatistikken for etterkrigstiden (Pedersen 1999) har imidlertid også vist at de største endringene har funnet sted ved de "klassiske institusjonene" (psykiatriske sykehus og sykehjem). Det er ved disse institusjonene vi både absolutt og relativt finner den største nedgangen i varigheten av oppholdene. Denne trenden har fortsatt også på 1990-tallet.

Fram til 1994 økte antall og andel av yngre pasienter drastisk ved sykehusavdelingene, men denne endringen ser ut til å ha stoppet opp etter 1994. Men fra 1994 til 1999 er det en tilsvarende økning av yngre pasienter i døgninstitusjoner utenfor sykehus, mens andelen eldre pasienter er redusert mest (Hagen 2001). Nedbyggingen av heldøgnsomsorgen har altså særlig vært knyttet til de eldre pasientene. Mens en har hatt en dramatisk nedgang i prevalenstallene for de eldste aldersgruppene, lå prevalenstallene for aldersgruppen under 40 år på omlag samme nivå på 1990-tallet som på slutten av 1970 tallet (Gråwe et al 1997).

Siden det i løpet av de siste årene har vært en økning i poliklinisk kapasitet og en reduksjon i antallet døgnplasser, er det av interesse å se om dette også fører til en endret fordeling av tilbudene. Kvinner og yngre pasientgrupper er markert overrepresentert $i$ alle typer poliklinisk praksis (Hagen 2001). Spesialister med selvstendig praksis har særlig høy andel kvinner, høy andel av aldersgruppene 40-59 år og høy andel pasienter med utdanning fra universitet eller høgskole. Mens mer enn halvparten av pasientene ved døgninstitusjonene har schizofreni eller andre alvorlige psykiske lidelser, har nitti prosent av pasientene hos spesialister i selvstendig praksis og 70 prosent av pasientene ved poliklinikkene mer moderate psykiske lidelser i form av personlighetsforstyrrelser, affektive lidelser og angstlidelser. Det er i samsvar med ønsker fra statlige helsemyndigheter at spesialister i selvstendig praksis i hovedsak skal gi tilbud til pasienter med mer moderate lidelser, mens poliklinikkene skal prioritere pasienter med mer alvorlige lidelser der det er større behov for samarbeid med andre instanser. Men dersom døgntilbudene for dem med alvorlige psykiske lidelser bygges ned uten en tilsvarende opprioritering av disse pasientgruppene når det gjelder tilbud utenfor 
døgninstitusjoner, vil det kunne skje en vridning av de samlede tilbud bort fra disse pasientgruppene og over til pasientgrupper med psykiske lidelser av mer moderat alvorlighetsgrad.

\section{Om pasientene fär den type hjelp de har behov for}

Ved pasientregistreringene av døgnpasienter hvert femte år er behandlerne bedt om å vurdere hva som er riktig eller ønskelig omsorgsnivå for den enkelte pasient, samt å angi pasientens vurdering eller ønske om det samme. Ved registreringen i 1999 vurderte behandlerne det slik at 1600 (30 prosent) av døgnpasientene burde hatt et annet tilbud innen psykisk helsevern, mens 1200 burde hatt kommunale tilbud. Det er altså mange pasienter som en mener ville ha klart seg med et mindre omfattende omsorgstilbud. Dette er mest markert ved akuttavdelinger, der behandlerne mente at 400 pasienter (53 prosent) burde hatt et annet tilbud. Disse burde heller ha vært ved korttids- og intermediæravdelinger (16 prosent), langtidsavdelinger (6 prosent), rehabiliteringsavdelinger ( 7 prosent), eller hatt andre tilbud innen psykisk helsevern (17 prosent) eller kommunale tilbud (6 prosent). Dette mønsteret har vært tilstede også ved tidligere pasientregistreringer, men tendensen til feil omsorgsnivå var større i 1999 enn tidligere. Denne type informasjon har av både statlige og fylkeskommunale helsemyndigheter, vært brukt som en av flere informasjonskilder for sin planlegging og videreutvikling av helsetjenestene. I pasientregistreringene ble det også spurt om hva som er pasientens eget ønske når det gjelder bo- og omsorgstilbud. Resultatene av dette har delvis vært $\mathrm{i}$ samsvar med de vurderinger behandlerne har gjort, men langt flere pasienter ønsker egen bolig enn det antall som ut fra behandlernes vurdering kan klare seg i egen bolig.

Bupdata omfatter ikke opplysninger om hvordan tilbudsstrukturen er tilpasset pasientenes behov, eller omfanget av og etterspørselen etter samarbeid med andre instanser. En viktig målsetting med pasientregistreringen for barn og unge i 1999/2000 var derfor å gi en oversikt over forholdet mellom tilbud og behov blant de barn og unge som mottok spesialiserte tilbud på registreringstidspunktet. Behandlernes vurderinger av hvorvidt pasientene mottok et adekvat behandlingstilbud og av hvilke behandlingsformer og typer tjenester som er mangelfulle, ble lagt til grunn for dette. Resultatene viser blant annet at flere av døgnpasientene enn dem som får det, trenger behandlingsformer som individualterapi og familieterapi, samt hjelpetiltak rettet mot hjem og familie. Videre viser resultatene at flere barn og unge ved døgninstitusjoner burde fått et annet tilbud. Over halvparten av pasientene ved akuttenhetene burde $\mathrm{i}$ henhold til behandlernes vurderinger hatt andre institusjonstilbud. Behandlerne mener videre at 16 prosent av barn og unge som mottar institusjonstilbud kunne vært utskrevet dersom de kommunale tilbudene var bedre. Resultatene fra pasientregistre- ringen avdekker også mangler ved det polikliniske tilbudet til barn og unge. Behandlernes vurderinger er at $i$ alt 32 prosent av de poliklinisk behandlede pasientene burde hatt andre behandlingstilbud i tillegg til det de faktisk mottar.

\section{Geografiske forskjeller i bruk av tjenester}

Med utgangspunkt i opplysninger fra den siste pasientregistreringen er det foretatt analyser av hvorvidt tilgjengeligheten av spesialiserte behandlingstilbud innen det psykisk helsevern for voksne er avhengig av type bosted. De ulike typer bosted er rangert langs et kontinuum med storbyen som det ene ytterpunktet og det lille bygdesamfunnet som det andre (Hagen 2002).

Resultatene viser at Oslo har i særklasse flest pasienter per innbygger. Også de andre byene har betydelig høyere punktprevalens enn øvrige kommunetyper. Byene har flest pasienter per innbygger ved alle de tre ulike behandlingstilbud (døgninstitusjoner, offentlige poliklinikker og private avtalespesialister), et mønster en ser for begge kjønn og alle diagnosegrupper. Den observerte overrepresentasjon av pasienter fra byene $\mathrm{i}$ forhold til mer spredt bebygde kommuner kan altså ikke tilbakeføres til ulik institusjonsstruktur.

Kommunene $\mathrm{i}$ den andre enden av aksen by-land de minste og antatt mest spredt bebygde og perifere kommunene - skiller seg ikke ut på tilsvarende måte. Andelen av befolkningen som mottar tilbud ved døgninstitusjoner og offentlige poliklinikker er omtrent like høy i store som i små landkommuner. Omfanget av privat avtalepraksis synker derimot drastisk med avtagende kommunestørrelse. Slik praksis drives hovedsakelig for befolkningen i byer og de største kommunene.

En finner store forskjeller i ressurser mellom helseregionene, der Helseregion Øst med Oslo skiller seg ut med mye mer ressurser enn andre steder. Men en finner ikke i samme grad forskjeller i tilbudet som gis. Når det gjelder polikliniske konsultasjoner for voksne per 10000 innbyggere ligger Helseregion Øst nær gjennomsnittet med 1561 konsultasjoner, mens Helseregion Sør har flest med 1655 og Helseregion Vest har færrest med 1229 konsultasjoner. Antall utskrivninger per 10000 innbyggere varierer relativt lite mellom regionene, med unntak av at region Øst har få utskrivninger fra institusjoner utenfor sykehus. På den andre siden er det en del variasjon $i$ antall oppholdsdøgn per 10000 innbyggere med størst bruk av døgnplasser i Helseregion Vest, noe som har sammenheng med antallet døgnplasser.

Data fra Bupdata har også vært analysert med tanke på geografiske forskjeller, f.eks. ved analyser av sammenheng mellom tilgjengelighet til spesialisert psykisk helsevern og pasientsammensetning, der utgangspunktet er fylkesvise variasjoner i andel barn og unge som mottar spesialiserte behandlingstilbud. Resultater tyder på at fylker som har en relativt høy terskel til et spesialisert psykisk helsetilbud prioriterer 
alvorlig syke pasienter, og at barn i den yngste aldersgruppen faller utenfor behandlingsapparatet i disse regionene (Andersson, 1999). Det har også vært gjort analyser med sammenligning av landlige områder (små kommuner) og bykommuner (store kommuner) med hensyn til hvor stor andel av befolkningen som mottar spesialiserte behandlingstilbud, samt egenskaper ved disse pasientene. Hovedfunnene i disse analysene er at barn og unge bosatt i småkommuner har en relativt god tilgjengelighet til psykisk helsevern, men er eldre ved henvisning og behandles for andre problemer enn barn bosatt i storkommuner.

Andre studier har omfattet analyser av institusjonsvise forskjeller i bruk av ressurser som tilføres pasienter innen en spesifikk diagnosegruppe, og hvorvidt slik variasjon kan forklares med forskjeller i pasientsammensetning. Resultatene viser at barn og unge med stemningslidelser i stor grad er en entydig gruppe med hensyn til den ressursinnsats som kreves i behandlingen, og videre at pasientkarakteristika som funksjonsnivå og alvorlighetsgrad ved diagnosen synes å forklare mye av de institusjonsvise forskjellene en finner (Andersson, 2000).

\section{Analyser av pasientforlop og reinnleggelser}

Innenfor psykisk helsevern finnes flere pasientgrupper med lidelser som medfører at de vil ha behov for langvarig behandling og oppfølging. For å kunne bedømme resultatet av behandlingen og det tilbudet som gis, må man kunne følge pasientene over tid. At institusjonene kan vise til økende aktivitet med flere og kortere opphold, betyr ikke nødvendigvis at flere pasienter får behandling. Dersom en pasient raskt blir innlagt igjen, eller har hyppige reinnleggelser, kan dette være en indikasjon på at oppholdene er for korte (Heggestad 1996). I en studie av pasientgjennomstrømningens betydning, fant en at pasienter utskrevet fra avdelinger med høyt tempo (målt som antall årlige utskrivinger pr seng), hadde en høyere risiko for snarlig reinnleggelse (Heggestad 2001).

\section{Arsaker til variasjon i tvangsinnleggelser}

Det er også gjort analyser av om ulik pasientsammensetning kan forklare forskjeller i tvangsinnleggelser $\mathrm{i}$ ulike områder i Norge (Bjørngaard og Heggestad 2001). Disse viste at en del av forskjellene mellom sykehusene i forekomst av tvangsinnleggelser skyldtes ulik pasientsammensetning målt med kjønn, alder, tidligere innleggelser og diagnose. Dette gjaldt imidlertid i større grad for tidsubegrenset tvangsinnleggelser enn ved tvangsinnleggelse til observasjon.

\section{DISKUSJON}

Tverrsnittsundersøkelsene har gitt mest komplette data og har vært nyttige for å følge utviklingen av psykisk helsevern over tid. Resultatene fra disse har også vært brukt av statlige og fylkeskommunale helsemyndigheter i planlegging av hvordan disse spesialisthelsetjenestene skal dimensjoneres og utvikles videre. Pasientdata som rapporteres fra institusjoner i psykisk helsevern for voksne til Norsk Pasientregister, har vært mye mer mangelfulle. Det er en langvarig og omfattende prosess å komme fram til en felles praksis for alle institusjonene i landet når det gjelder kontinuerlig registrering og enhetlig rapportering av opplysningene. En slik innsamling og rapportering av longitudinelle data er både avhengig av tilgang på pasientadministrative datasystem, og ikke minst omfattende opplæring og monitorering av personalet som skal registrere slike data $i$ en presset arbeidssituasjon der dette ofte har lav prioritet. Det arbeides imidlertid mye med disse forholdene, og det forventes at disse longitudinelle data blir mer komplette i løpet av de nærmeste årene. En begrensende faktor når en skal følge utviklingen av psykisk helsevern over tid, er at en ikke har person-identifiserbare data eller andre tilgjengelige metoder for å koble data om samme person innen det samme nasjonale pasientregisteret. Dette gjør det vanskelig å analyser problemstillinger som reinnleggelser eller mønstre for bruk av flere institusjoner ved samme person.

Vinteren 2002 har Kompetansesenter for IT i helsevesenet (KITH) og Norsk Pasientregister arbeidet med å legge om og forbedre datastruktur, innhold og rapporteringsmåte for obligatoriske datasett. Det vil også i løpet av 2002 bli gjort en systematisk gjennomgang og standardisering av kategorisering både av institusjoner og avdelinger for å sikre mer pålitelig sammenligning av data mellom institusjoner og enheter av samme type. Dette vil sammen med økende interesse for bruk av data lokalt, på sikt kunne bidra til bedre datakvalitet og muligheter for nye typer analyser.

\section{REFERANSER}

American Psychiatric Association (1994). Diagnostic and Statistical Manual of Mental Disorders, Fourth Edition. American Psychiatric Association, Washington DC.

Andersson HW (1999). Behandlingsomfang og pasientsammensetninger i barne- og ungdomspsykiatrien. I: Hagen H (red.), Samdata Psykiatri Rapport, 6, 91-106.

Andersson HW (2000). Barn og unge med stemningslidelser: Karakteristika ved pasienter og behandlingstilbud i BUP. I: Hagen H (red.), Samdata Psykiatri Rapport, 4/00, 95-105. 
Andersson HW (2001). Barn og unge med psykiske lidelser. Karakteristika ved pasientene og det spesialiserte behandlingstilbudet. Sintef Unimed, Helsetjenesteforskning. Rapport 4/01.

Andersson HW (2002). Geografisk ulikhet i bruk av tjenester for barn og unge. Samdata psykisk helsevern Rapport 2001. Kap. 7 i SINTEF Unimed rapport 7/01.

Bjørngaard JH (red.) (2001). SAMDATA Psykisk helsevern. Tabeller. Sammenligningsdata for psykisk helsevern 2000. SINTEF Unimed rapport 6/01. SINTEF Unimed, Trondheim.

Bjørngaard JH, Heggestad T (2001). Kan ulik pasientsammensetning forklare forskjeller i tvangsinnleggelser? Tidsskr Nor Lageforen 121: 3369-3374.

Gråwe RW, Pedersen PB, Widén JH (1997). Changes in prevalence and comorbidity in a total population of patients with psychotic disorders in Norwegian psychiatric hospitals. Nord J Psychiatry 51: 127-132.

Götestam KG, Eriksen L, Hagen H (1995). An epidemiological study of eating disorders in Norwegian psychiatric institutions. Int J Eating Disord 18: 263-268.

Götestam KG, Eriksen L, Heggestad T, Nielsen S (1998). Prevalence of eating disorders in Norwegian general hospitals 1990-1994: Admissions per year and seasonality. Int J Eating Disord 23: 57-64.

Hagen H (1987). Hvem blir pasienter i psykiatriske institusjoner? En epidemiologisk registerstudie. SINTEF/NIS Rapport 1/87. SINTEF Norsk institutt for sykehusforskning, Trondheim.

Hagen H (1991). Suicidal attempts among psychiatric patients. In: Bjerke T, Stiles TC (eds.), Suicide attempts in the Nordic countries. Epidemiology and treatment. Tapir, Trondheim.

Hagen H (1992). Pasienter i psykiatriske institusjoner 1. november 1989. SINTEF/NIS Rapport 6/92. SINTEF Norsk institutt for sykehusforskning, Trondheim.

Hagen H (1997). Pasienter i psykiatriske institusjoner 1. november 1994. SINTEF/NIS Rapport 5/97. SINTEF Norsk institutt for sykehusforskning, Trondheim.

Hagen H (red.) (1999). SAMDATA psykiatri rapport. Psykiatritjenesten 1998 - på rett vei? SINTEF Unimed rapport 6/99. SINTEF Unimed, Trondheim.

Hagen H (red.) (2000). SAMDATA psykiatri rapport. Psykiatritjenesten 1999 - omstillinger og vekst. SINTEF Unimed rapport 4/00. SINTEF Unimed, Trondheim.

Hagen H (2001). Pasienter i psykisk helsevern for voksne 1. november 1999. SINTEF Unimed rapport 5/01. SINTEF Unimed, Trondheim.

Hagen H (2002). Geografisk ulikhet i tilgjengelighet til tjenester for voksne. Kap. 8 i Samdata psykisk helsevern Rapport 2001, SINTEF Unimed rapport 7/01. SINTEF Unimed, Trondheim.

Halsteinli V (1997): Samdata psykiatri. Sammenligningsdata for psykiatrisk fylkeshelsetjeneste 1996. SINTEF/NIS Rapport 8/97. Del 1 Rapportdel. Del 2 Tabelldel. SINTEF Norsk institutt for sykehusforskning, Trondheim.

Halsteinli V (red.) (1998). SAMDATA psykiatri rapport. Psykiatritjenesten på 90-tallet. SINTEF Unimed rapport 5/98. SINTEF Unimed, Trondheim.

Halsteinli V (red.) (1998). SAMDATA psykiatri tabeller 1997. Sammenligningsdata for psykiatrisk fylkeshelsetjeneste 1997. SINTEF Unimed rapport 6/98. SINTEF Unimed, Trondheim.

Halsteinli V (red.) (1999). SAMDATA psykiatri tabeller. Sammenligningsdata for psykiatrisk fylkeshelsetjeneste 1998. SINTEF Unimed rapport 7/99. SINTEF Unimed, Trondheim.

Halsteinli V (red.) (2000). SAMDATA psykiatri tabeller. Sammenligningsdata for psykiatrisk fylkeshelsetjeneste 1999. SINTEF Unimed rapport 5/00. SINTEF Unimed, Trondheim.

Hatling T (1997): Samdata psykiatri. Sammenligningsdata for psykiatrisk fylkeshelsetjeneste 1995. SINTEF/NIS Rapport 2/97. Del 1 Rapportdel. Del 2 Tabelldel. SINTEF Norsk institutt for sykehusforskning, Trondheim.

Heggestad T (1993). Nasjonalt pasientdatasett for voksenpsykiatri 1992. Et forprosjekt. NIS-prosjektrapport $\mathrm{nr} 7$, 1993.

Heggestad T (1996). Forbruk. Behandling. Pasienter. Reinnleggelser. I Pedersen PB (red.) SAMDATA PSYKIATRI. Sammenligningsdata for psykiatrisk fylkeshelsetjeneste 1994. NIS-rapport 1/96.

Heggestad T, Pedersen PB (1995). Samdata psykiatri. Sammenligningsdata for psykiatrisk fylkeshelsetjeneste 1993. SINTEF/NIS Rapport 1/95. SINTEF Norsk institutt for sykehusforskning, Trondheim.

Heggestad T (2001). Operating conditions of psychiatric hospitals and early readmission - effects of high patient turnover. Acta Psychiatr Scand 103: 196-202.

Kodebok for BUP (1999). Norsk forening for barne- og ungdomspsykiatriske institusjoner.

Kolstad A (1988). Pasienter med misbruksproblematikk i norske psykiatriske institusjoner. Tidsskr Nord Alkoholforsk 5: 176-184.

Kolstad A, Hagen H (1988). Hvor vil psykiatriske pasienter være? Om institusjonaliseringens betydning for pasientenes ønske om fremtidig bo- og behandlingstilbud. Nord Psykol 40: 161-170.

Pedersen PB, Bergsland KH (1993): Samdata psykiatri. Sammenligningsdata for psykiatrisk fylkeshelsetjeneste 1991. SINTEF/NIS Rapport 1/93. SINTEF Norsk institutt for sykehusforskning, Trondheim. 
Pedersen PB, Heggestad T, Bergsland KH (1994): Samdata psykiatri. Sammenligningsdata for psykiatrisk fylkeshelsetjeneste 1992. SINTEF/NIS Rapport 1/94. SINTEF Norsk institutt for sykehusforskning, Trondheim.

Pedersen PB (1996): Samdata psykiatri. Sammenligningsdata for psykiatrisk fylkeshelsetjeneste 1994. SINTEF/ NIS Rapport 1/96. SINTEF Norsk institutt for sykehusforskning, Trondheim.

Pedersen PB (1999): De-institusjonaliseringen av psykiatritjenesten i Norge 1950-96. En statistisk dokumentasjon. NIS Minirapport. SINTEF Unimed STF78 M99504, Trondheim.

Pedersen PB (2002): Samdata psykisk helsevern Rapport 2001. SINTEF Unimed rapport 7/01. SINTEF Unimed, Trondheim.

Ruud T, Friis S, Løvdahl H, Bakke O (1993). Bruk av minste basis datasett i psykiatriske helsetjenester. Statens helsetilsyn, Oslo, IK 2421.

Øgar B (1981). Pasienter i psykiatriske institusjoner 1. november 1979. SINTEF/NIS Rapport 5/81. SINTEF Norsk institutt for sykehusforskning, Trondheim.

Øgar B (1983). Psykiatriske sykehjem i dag - morgendagens psykiatriske bo- og behandlingssentra? SINTEF/NIS Rapport 5/81. SINTEF Norsk institutt for sykehusforskning, Trondheim.

Øgar B, Kolstad A, Kindseth O (1986). Pasienter i psykiatriske institusjoner 1. november 1984. SINTEF/NIS Rapport 5/85. SINTEF Norsk institutt for sykehusforskning, Trondheim. 